\title{
EFFICACY OF WEIGHT BEARING EXERCISES FOR SYSTEMIC LUPUS ERYTHEMATOSUS PATIENTS SUFFERED FROM OSTEOPOROSIS
}

\section{Instar S. Waked*}

* Assistant Professor of physical therapy, Faculty of physical therapy, Cairo University, Egypt.

\section{ABSTRACT}

Objective: the aim of this study was to evaluate the efficacy of weight bearing exercises for systemic lupus erythematosus patients suffered from osteoporosis

Methods: Forty patients were randomly divided into two groups of equal number. Exercise group (E) received weight-bearing exercises and the control group $(C)$ didn't receive any type of exercise. Bone mineral density was measured by Dual X-ray absorptiometry at the beginning of the study and after 2 months for all patients.

Results: The results showed that there were significant positive changes in bone mineral density in exercise group while there was a decrease in Bone mineral density in control group.

Conclusion: It could be concluded that weight bearing exercises program have a significant improvement effect in bone mineral density in systemic lupus erythematosus patients suffered from osteoporosis.

KEY WORDS: Weight Bearing Exercises, Bone Mineral Density, Systemic Lupus Erythematosus, Osteoporosis.

Address for correspondence: Dr. Instar S. Waked, Assistant Professor of physical therapy, Faculty of physical therapy, Cairo University, Egypt. Address: 17th Ahmed El-Zyat Street, Faculty of Physical Therapy, Cairo University. Cairo, Egypt.,Mobile NO.: +966532107885 E-Mail: I.waked@mu.edu.sa

\section{Access this Article online}

Quick Response code

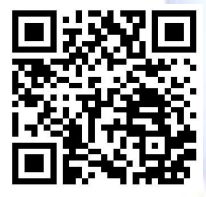

DOI: $10.16965 /$ ijpr.2017.234
International Journal of Physiotherapy and Research

ISSN 2321- 1822

www.ijmhr.org/ijpr.html

Received: 13-09-2017 Accepted: 19-10-2017

Peer Review: 13-09-2017

Published (0): 11-11-2017

Revised: None

Published (P): 11-12-2017

\section{INTRODUCTION}

Systemic lupus erythematosus (SLE) is a chronic inflammatory autoimmune disease of unknown etiology. Mortality and morbidity result from the disease activity and its treatment [1,2]. Despite the development of new treatments, glucocorticoid remains the main stay of management of SLE. The use of glucocorticoids in SLE is associated with some side effects and is the major cause of organ damage. Of the various complications of chronic glucocorticoid treatment in SLE patients, osteoporosis and its consequences are among the most serious $[3,4]$.

Systemic intake of corticosteroids is a wellknown cause of osteoporosis [5], and corticosteroids affect the bone in several ways. They cause diminished bone formation and increased bone resorption. Also, they decrease intestinal calcium absorption, increase urinary calcium excretion, and disturb vitamin D metabolism.[6] Some studies [7-12] have addressed the problem of low BMD in patients with SLE. Osteoporosis occurs in up to $24 \%$ of patients at the lumbar spine and $23 \%$ at the femoral hip. In general, the loss of BMD is more severe at the spine than the hip, which is consistent with the predominant effect of glucocorticoids on trabecular bones [13].

Besides long term glucocorticoid treatment, SLE patients are particularly prone to osteoporosis because of renal insufficiency, premature ovarian failure, avoidance of sun exposure, disabling arthritis and myopathy, failure to achieve a peak bone mass and the use of other medications 
such as anticoagulants and anticonvulsants[10].

Osteoporosis is a major public health concern. It is a silent heterogenous skeletal disease of multifactorial origin characterized by excessively low bone density, bone fragility, and increased risk of fracture with relatively minor trauma. The disease has a high prevalence in middle-aged and older adults [14,15]. Exercise, nutrition, and medication are currently recommended for the prevention and treatment of osteoporosis [16]. Weight bearing exercise is the exercise that makes body works against gravity. Regular weight bearing exercises help to produce strong bone and are good options for promoting healthy bones [17].

Physical activity in specific programmed weightbearing exercises may protect postmenopausal against rapid decline in bone mass. There is little literature document the effect of weight bearing exercises on SLE patients suffered from osteoporosis. Therefore, this study was designed to determine the clinical evidence for the effectiveness of weight bearing exercises on patients with SLE suffered from osteoporosis.

\section{PATIENTS AND METHODS}

Patients: Forty patients with SLE who suffered from osteoporosis participated in the study. They were selected from Al-Kaser Eini Hospital between June 2015 to September 2017. Patients were randomly classified into two groups of equal number; Group (E): (Exercises Group) that included twenty patients and received weight bearing exercises for fifty minutes twice per week for two months [18]. Group (C): (control group); they included twenty patients and did not receive any exercise, but they were encouraged to maintain their ordinary level of physical activity during the study period. Each patient was informed verbally and in writing about the trial and all of them gave their written consent. The criteria for patients' selection were classified into two various categories; inclusion criteria included; their ages above 45 years, both sexes were included, they had already received oral corticosteroids daily for at least six months, patients with $\mathrm{BMD} \leq-2.5$. Patients in a good psychological state to continue the exercise program. Any patient should sign consent form prior to participation. Exclusion criteria included;
Patients who were receiving medical treatment for osteoporosis, hyperparathyroidism, alcoholism, Heavy smoker, body mass index (BMI) of 19 or less, patients who had any other disease that may restrict performing the exercise program, patients with a bad psychological state to start or continue the treatment.

\section{Methods}

\section{Measurement of bone density}

\section{Measuring equipment:}

Dual X-ray absorptiometry (DXA) is the most commonly used method to measure bone mineral density (BMD) due to its high accuracy, short scan times, and stable calibration in clinical uses. DXA apparatus allows scanning of the following sites lumbar spine, proximal femur, and distal forearm. These sites are regarded as the most important measurement sites as they are frequent sites for fractures that cause impairment of the quality of life and increased morbidity and mortality. Assessment of BMD in these sites is an accurate marker for osteoporosis that helps to identify the risk for fracture [19].

Fig. 1: Dual Energy X-ray Absorptiometry device.

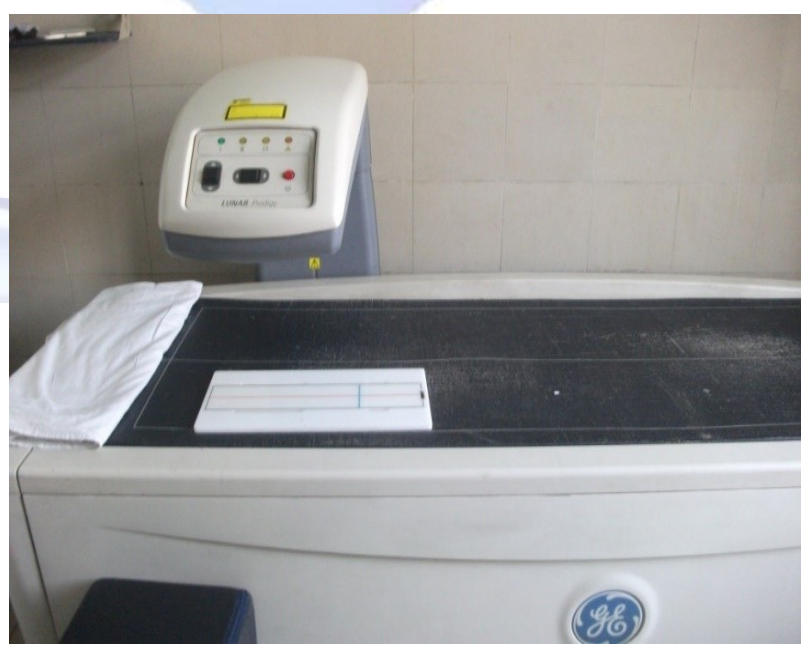

Measurement procedures: All DXA measurements were done on DXA apparatus (GE, Lunar scanner, Madison Wis) fig (1). The technologist performed a quality cont rol check for apparat us before the beginning of measurement according to the manufacturer's instructions.

BMD measurements were conducted lumbar spine, left hip, and left forearm. The patients lay supine on imaging table and his legs raised and supported by lumbar spine measurement. For hip measurements, The patient s lay supine on imaging table and his legs flat on the imag- 
ing table with feet strapped to a feet holder that position the measured leg at $30^{\circ}$ inward rotation. The patient sat beside the table with the arm supported on imaging table for forearm measurement. L2-L4 is used as a reference for lumbar spine, the total femur for the proximal femur, and the one-third-radius for the forearm BMD measurements. Bone density measurement was conducted before the first session and after two months of treatment. The density results of these bones were then compared with an average index based on age, sex fig(2). The resulting comparison is used to detect risk for fractures and the stage of osteoporosis in an individual.

Average bone mineral density $=\mathrm{BMC} / \mathrm{W}\left(\mathrm{g} / \mathrm{cm}^{2}\right)$. ( $\mathrm{BMC}=$ bone mineral content $=\mathrm{g} / \mathrm{cm}, \mathrm{W}=$ width at the scanned line) $[20,21]$.

Fig. 2: Example DEXA chart and results

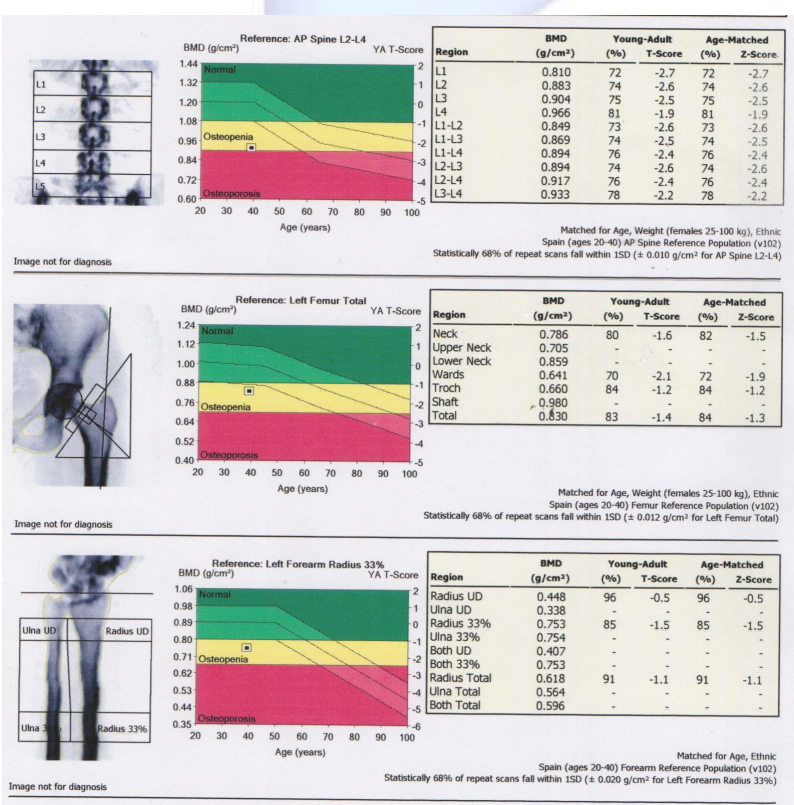

Treatment procedures: In this study, the treatment protocol was presented for Group (E) in the form of an exercise program lasted for 50 minutes [18], twice weekly and consisted of different weight bearing phases that achieved under the following phases; warming up, exercises, cooling down phase.

Warming up phase: The main aim of this phase was to get the muscles warm and loose for strength training. The patient has to train for ten minutes on a stationary bicycle at a mild velocity before the beginning of each exercise session. Bicycling helps direct needed blood flow to the muscles and prepares the body for exercise. Warming up is important for preventing injury as well as gaining maximal benefit from the exercise because loose and warm muscles respond better to the challenge of the program [18].

Exercise program phase: Exercise program phase consisted of three stages of exercises. Each stage contained a group of weight bearing exercises that focused on certain muscle groups and body parts aiming to load and impact the skeleton through both body weight and muscle action to stimulate the further bone formation and to increase bone density [18].

Stage 1: It consisted of four types of exercises and lasted for three weeks. The four types of exercises were; squats for five minutes, wall pushups for five minutes, toe stands for five minutes, walking on a treadmill for fifteen minutes fig (3).

Stage 2: This stage lasted three weeks and included four types of exercises; biceps curl for five minutes, step-ups for five minutes, hip abduction for five minutes, walking on a treadmill for fifteen minutes.

Stage 3: This stage lasted two weeks and included three types of exercises; Knee extension for five minutes, knee curl for five minutes, walking on a treadmill for twenty minutes.

Cooling down phase: It is of great importance to cool down after exercises to prevent muscle pain and sourness that may follow an unaccustomed physical effort. Cooling down should be performed for ten minutes at the end of each exercise session. It consisted of the following exercises; Quadriceps stretch, Hamstring and calf stretch, Chest and arm stretch, Neck, upper back and shoulder stretch [18].

Warming up and cooling down are essential parts of the exercise program. They should be done before and after each session respectively, and they are included in the total time of the session. Exercise program was progressed to other stage according to the patient ability through exercises intensity indicator fig (4).

Statistical procedures and data analysis: Data were encoded and entered using Microsoft Excel version 13 (Microsoft Corporation, NY, USA) and SPSS (Statistical Package for the Social Sciences; SPSS Inc., Chicago, IL, USA) statistical program. Data were statistically described in 
terms of range, mean, standard deviation (SD), median, frequencies (number of cases), and relative frequencies (percentages) whenever appropriate. Comparison of quantitative data between both groups in the present study was done using Student's t-test for independent samples that were normally distributed and the Mann Whitney $U$ test for independent samples when they were not normally distributed. Paired$t$ test for comparison between pre and post treatment measurements of BMD in each group and Wilcoxon signed rank for data that were not normally distributed. Chi square2 test was used to compare data between the sexes. A probability value $(P)$ less than 0.05 was considered statistically significant.

Fig. 4: Exercises Intensity Indicator.

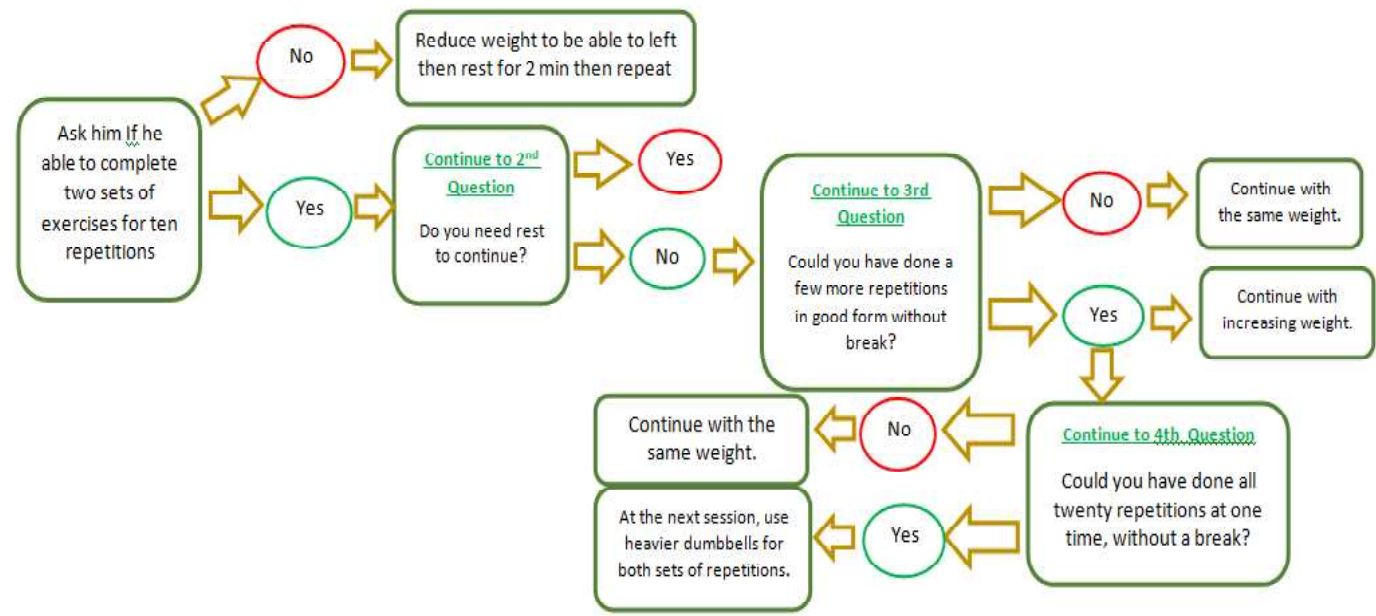

Note 1: Remember that the patient should complete each repetition in proper form, using the "two-up, four-down" count.

\section{RESULTS}

Patient demographic data and Initial clinical assessment: The patient demographic data including, age, sex, duration of SLE, causes of osteoporosis, cumulative doses of glucocorticoid were recorded, compared and analyzed for both groups. The clinical examinations included measurements of height and weight for calculation of $\mathrm{BMI}\left(\mathrm{BMI}=\right.$ weight $/$ height $\left.^{2}\right)$. Bone mineral density (BMD) was measured at lumbar, hip and forearm sites for all patients in both groups before and after two months of treatment.

Comparing patient demographic data for both groups revealed that there was no significant differences between both groups regarding age, sex, duration of SLE, causes of osteoporosis and
Fig. 3: Motorized treadmill.

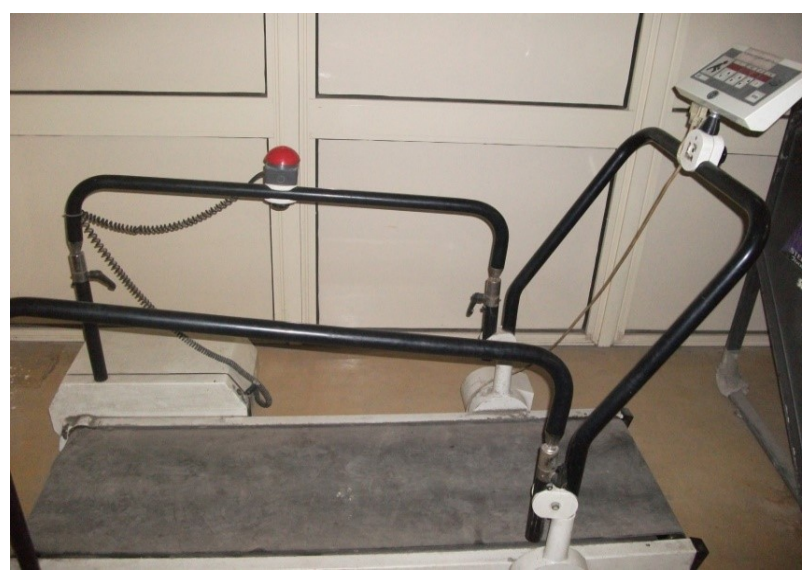

the cumulative doses of glucocorticoid as $(p>0.05)$.

Initial clinical assessment (weight, height, BMI, BMD at lumber, hip, forearm were compared before treatment and revealed no significant differences between both groups as $(p>0.05)$ as shown in the Table (1).

\section{Bone mineral density (BMD) results:}

Pre and post treatment mean values of BMD of exercise group: Table (2) showed that the pre-treatment mean values of BMD at lumbar, hip, forearm for exercises group were $0.844 \pm 0.125 \mathrm{~g} / \mathrm{cm}^{2}, 0.777 \pm 0.085 \mathrm{~g} / \mathrm{cm}^{2}$, and $0.630 \pm 0.050 \mathrm{~g} / \mathrm{cm}^{2}$ while post-treatment mean values of $B M D$ were $0.928 \pm 0.084 \mathrm{~g} / \mathrm{cm}^{2}$, $0.797 \pm 0.079 \mathrm{~g} / \mathrm{cm}^{2}$ and $0.660 \pm 0.049 \mathrm{~g} / \mathrm{cm}^{2}$. The mean differences between pre and post treatment were $0.08,0.02,0.03$ and the percentages 
of improvement were $10 \%, 2.6 \%, 4.8 \%$. There was a significant increase in $\mathrm{BMD}$ in exercise group post treatment compared with pretreatment $(p<0.000)$.

Table 1: Comparison of patient demographic data and initial clinical assessment (age, sex, duration of SLE, causes of osteoporosis and the cumulative doses of glucocorticoid, weight, height, and BMI, BMD at lumber, hip, forearm between both groups (Exercise and Control) before treatment.

$\overline{\mathrm{X}}$ : Mean, $\mathrm{p}$ value: Probability value $S D$ : Standard Deviation, $t$ value: Unpaired t value, NS: Non significant.

\begin{tabular}{|c|c|c|c|c|c|c|}
\hline \multicolumn{2}{|c|}{ Variable } & Exercise group & Control group & $\mathrm{t}$ - value & $p$-value & Sig \\
\hline \multicolumn{2}{|c|}{$\begin{array}{l}\text { Age (years) } \\
\bar{X} \pm S D\end{array}$} & $53.60 \pm 5.53$ & $54.30 \pm 4.13$ & -0.454 & 0.653 & NS \\
\hline \multicolumn{2}{|c|}{$\operatorname{Sex}(M / F) N / \%$} & $\begin{array}{c}5(25 \%) / 15 \\
(75 \%)\end{array}$ & $\begin{array}{c}4(20 \%) / 16 \\
(80 \%)\end{array}$ & $\begin{array}{c}\text { z value } \\
0.374\end{array}$ & 0.708 & NS \\
\hline \multicolumn{2}{|c|}{$\begin{array}{l}\text { Weight (kg) } \\
\bar{X} \pm S D\end{array}$} & $76.95 \pm 10.25$ & $76.85 \pm 10.80$ & 0.03 & 0.976 & NS \\
\hline \multicolumn{2}{|c|}{$\begin{array}{l}\text { Height (cm) } \\
\bar{X} \pm S D\end{array}$} & $165.65 \pm 6.43$ & $166.85 \pm 6.41$ & -0.591 & 0.558 & NS \\
\hline \multicolumn{2}{|c|}{$\begin{array}{c}\mathrm{BMI}\left(\mathrm{kg} / \mathrm{m}^{2}\right) \\
\overline{\mathrm{X}} \pm \mathrm{SD}\end{array}$} & $28.06 \pm 3.42$ & $27.71 \pm 4.41$ & 0.281 & 0.78 & NS \\
\hline \multicolumn{2}{|c|}{$\begin{array}{l}\text { duration of SLE } \\
\bar{X} \pm S D\end{array}$} & $28.10 \pm 12.06$ & $29.10 \pm 11.39$ & -0.27 & 0.789 & NS \\
\hline \multirow{5}{*}{ 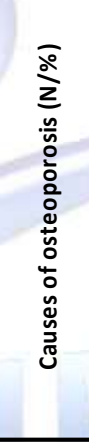 } & $\begin{array}{l}\text { Steroid } \\
\text { therapy }\end{array}$ & $11(55 \%)$ & $13(65 \%)$ & \multirow{5}{*}{$\begin{array}{l}\text { z value } \\
0.637\end{array}$} & \multirow{5}{*}{0.462} & \multirow{5}{*}{ NS } \\
\hline & $\begin{array}{c}\text { renal } \\
\text { insufficiency }\end{array}$ & $3(15 \%)$ & $4(20 \%)$ & & & \\
\hline & $\begin{array}{c}\text { not exposed } \\
\text { to sun }\end{array}$ & $3(15 \%)$ & $1(5 \%)$ & & & \\
\hline & $\begin{array}{c}\text { premature } \\
\text { ovarian } \\
\text { failure }\end{array}$ & $1(5 \%)$ & $(10 \%) 2$ & & & \\
\hline & Inactivity & $2(10 \%)$ & $(0 \%) 0$ & & & \\
\hline \multicolumn{2}{|c|}{$\begin{array}{l}\text { High dose of steroid } \\
\qquad(\mathrm{N} / \%)\end{array}$} & $11(55 \%)$ & $13(65 \%)$ & $\begin{array}{c}z \text { value } \\
0.637\end{array}$ & 0.524 & NS \\
\hline \multicolumn{2}{|c|}{$\begin{array}{l}\text { cumulative doses of } \\
\text { glucocorticoid }\end{array}$} & $9.31 \pm 2.62$ & $10.84 \pm 3.49$ & 1.574 & 0.124 & NS \\
\hline \multicolumn{2}{|c|}{ BMD at lumber (pre) } & $0.844 \pm 0.125$ & $0.866 \pm 0.087$ & 0.644 & 0.524 & NS \\
\hline \multicolumn{2}{|c|}{ BMD at hip (pre) } & $0.777 \pm 0.085$ & $0.827 \pm 0.090$ & 1.881 & 0.068 & NS \\
\hline \multicolumn{2}{|c|}{ BMD at forearm (pre) } & $0.630 \pm 0.049$ & $0.641 \pm 0.054$ & 0.673 & 0.505 & NS \\
\hline
\end{tabular}

Table 2: Comparison between pre and post treatment mean values of $\mathrm{BMD}\left(\mathrm{g} / \mathrm{cm}^{2}\right)$ of exercise group.

\begin{tabular}{|c|c|c|c|c|c|c|}
\hline & $\mathrm{BMD}\left(\mathrm{g} / \mathrm{cm}^{2}\right)$ & \multirow{2}{*}{ MD } & \multirow{2}{*}{$\begin{array}{c}\% \text { of } \\
\text { improvem }\end{array}$} & \multirow{2}{*}{$\mathrm{t}$ - value } & \multirow{2}{*}{$p$-value } & \multirow{2}{*}{ Sig } \\
\hline & $\bar{X} \pm S D$ & & & & & \\
\hline BMD at lumber (pre) & $0.844 \pm 0.125$ & \multirow{2}{*}{0.08} & \multirow{2}{*}{$10 \%$} & \multirow{2}{*}{-4.509} & \multirow{2}{*}{0} & \multirow{2}{*}{ HS } \\
\hline BMD at lumber (post) & $0.928 \pm 0.084$ & & & & & \\
\hline BMD at hip (pre) & $0.777 \pm 0.085$ & \multirow{2}{*}{0.02} & \multirow{2}{*}{$2.60 \%$} & \multirow{2}{*}{-7.118} & \multirow{2}{*}{0} & \multirow{2}{*}{ HS } \\
\hline BMD at hip (post) & $0.797 \pm 0.079$ & & & & & \\
\hline BMD at forearm (pre) & $0.630 \pm 0.050$ & \multirow{2}{*}{0.03} & \multirow{2}{*}{$4.8 \%$} & \multirow{2}{*}{-3.839} & \multirow{2}{*}{0.001} & \multirow{2}{*}{ HS } \\
\hline BMD at forearm (post) & $0.660 \pm 0.049$ & & & & & \\
\hline
\end{tabular}

MD: Mean difference, $t$ value: Paired $t$ value, $p$ value: Probability value, HS: highly Significant, $\overline{\mathrm{X}}$ : Mean, SD: Standard Deviation.

Table 3: Comparison between pre and post treatment mean values of $\mathrm{BMD}\left(\mathrm{g} / \mathrm{cm}^{2}\right)$ of control group.

\begin{tabular}{|c|c|c|c|c|c|c|}
\hline \multirow{2}{*}{ Variable } & $\mathrm{BMD}\left(\mathrm{g} / \mathrm{cm}^{2}\right)$ & \multirow{2}{*}{ MD } & \multirow{2}{*}{$\begin{array}{c}\% \text { of } \\
\text { change }\end{array}$} & \multirow{2}{*}{ t- value } & \multirow{2}{*}{$p$-value } & \multirow{2}{*}{ Sig } \\
\hline & $\overline{\mathrm{X}} \pm$ SD & & & & & \\
\hline BMD at lumber (pre) & $0.866 \pm 0.087$ & \multirow{2}{*}{0.008} & \multirow{2}{*}{$-0.92 \%$} & \multirow{2}{*}{1.185} & \multirow{2}{*}{0.251} & \multirow{2}{*}{ NS } \\
\hline BMD at lumber (post) & $0.858 \pm 0.084$ & & & & & \\
\hline BMD at hip (pre) & $0.827 \pm 0.090$ & \multirow{2}{*}{0.036} & \multirow{2}{*}{$-4.20 \%$} & \multirow{2}{*}{1.64} & \multirow{2}{*}{0.117} & \multirow{2}{*}{ NS } \\
\hline BMD at hip (post) & $0.791 \pm 0.099$ & & & & & \\
\hline BMD at forearm (pre) & $0.654 \pm 0.051$ & \multirow{2}{*}{0.006} & \multirow{2}{*}{$-0.91 \%$} & \multirow{2}{*}{1.565} & \multirow{2}{*}{0.134} & \multirow{2}{*}{ NS } \\
\hline BMD at forearm (post) & $0.648 \pm 0.058$ & & & & & \\
\hline
\end{tabular}

MD: Mean difference, $t$ value: Paired t value, $\mathbf{p}$ value: Probability value, HS: highly Significant, $\overline{\mathrm{X}}$ : Mean, SD: Standard Deviation. 
Pre and post treatment mean values of BMD of control group: Table (3) showed that the pre-treatment mean values of BMD at lumbar, hip, forearm for control group were $0.866 \pm 0.087 \mathrm{~g} / \mathrm{cm}^{2}, 0.827 \pm 0.090 \mathrm{~g} / \mathrm{cm}^{2}$, and $0.654 \pm 0.051 \mathrm{~g} / \mathrm{cm}^{2}$ while post-treatment mean values of BMD were $0.858 \pm 0.084 \mathrm{~g} / \mathrm{cm}^{2}$, $0.791 \pm 0.099 \mathrm{~g} / \mathrm{cm}^{2}$ and $0.654 \pm 0.058 \mathrm{~g} / \mathrm{cm}^{2}$. The mean differences between pre and post treatment were $0.008,0.036,0.006$ and the percentages of change were $-0.92 \%,-4.2 \%,-0.91 \%$.

\section{DISCUSSION}

Bone weakness occurs in SLE due to several reasons; firstly, it is due to the disease itself since abnormalities in the immune system, such as an imbalance of inûammatory cytokines including inter-leukin-6, which is involved in the pathogenesis of accelerated bone remodeling, have been observed. Secondly, decreased physical activity due to arthritis must be taken into account. Prevention strategies therefore including any type of exercises such as weight bearing in everyday life, because it is known that among SLE patients, especially in corticosteroid exposed subjects; regular exercise is protective of bone mineral density loss [22-24]. Exercise is a valuable adjunct to programs aimed at alleviating the risks and symptoms of osteoporosis [25].

The findings of the current study indicated a significant increase in BMD at lumbar spine, right neck of femur, and right distal radial head occurred after application of weight bearing exercises program for exercise group. In contrast, there was decrease in BMD at lumbar spine, right neck of femur, and right distal radial head from the beginning to the end of the study duration in control group. The significant positive changes of "BMD" in Group E than Group $C$ indicated that weight bearing had more influence on BMD.

The scientific explanations of these results that proved the efficacy of weight bearing exercises on bone mineral density are:

Bone tissue responds to repeated mechanical deformation and muscular contractions that leads to an increase in pulsed electric currents in bone via piezoelectric effects. When mechanical forces through mechanical loads during erercise are converted into electrical stimulus, particular bone tissue cells can begin the osteogenesis process increasing BMD.

Bones, like muscles, respond to stress by becoming bigger and stronger. Regular physical exercise puts physical stress on the body, helping to stimulate bone growth and maintain bone mass, and affords excellent general health benefits, the foremost being an increase in BMD. There is strong evidence that physical activity begun early in life provides higher peak bone mass. Peak bone mass and subsequent bone mineral maintenance is mostly affected by the interplay between mechanical stress, body composition, and nutrition and bone metabolism. Activities such as resistance training and weight bearing exercises are likely to be more beneficial because they help to build bones and preserve bone mass [26].

Weight bearing activity stimulates bone remodeling [27].

The results of this study regarding BMD are in agreement with previous studies conducted by Qin et al., [26], Kohert et al., [28], Rockville [29], Bouxsein [30], Meka et al., [31], Seigrist [27], Caplan et al., [32], and Kai et al., [25].

Qin et al., [26], mentioned that activities such as resistance training and weight bearing exercises are likely to be more beneficial because they help to build bones and preserve bone mass. Kohert et al., [28], reported that Current national and international consensus osteoporosis management guidelines recommend a combination of weight bearing and resistance training with challenging balance exercises to improve multiple risk factors for falls and fractures. Rockville [29], mentioned that exercise had been shown to be essential for maximizing peak bone mass and reducing subsequent bone loss. Also, Bouxsein [30], stated that high-impact exercise had been suggested to be the most eûective regimen, and it has been suggested that induced gain is maintained after intervention.

Meka et al., [31], noted that Physical activity is the modifiable factor that can enhance bone accretion if the individual performs regularly. Weight bearing activity has been shown to increase bone accretion more than non-weight bearing activity. 
Seigrist [27], highlighted that overall, the evidence strongly suggests that regular physical activity, especially started in childhood and adolescence, was a cheap and safe way of both improving bone strength and reducing the risk to fall.

Caplan et al., [32], reported that twice-weekly weight bearing aerobic exercise sessions had a protective effect on bone density in postmenopausal women besides associated with other measurable benefits.

Kai et al., [25] stated that recent prospective studies conducted in Denmark have shown that keeping of leisure physical activity at a moderate level seems to protect against hip fracture in later life, and that diminish physical activity is associated with greater risk of hip fracture. Regular moderate physical activity can help improve balance, strength, and coordination, thereby reducing the risk of falls and resulting injuries.

This study had some limitations; the number of patients was relatively small. Therefore, a larger sample size would provide a better insight into the efficacy of the weight bearing program. The measurements were done only before and after treatment without further follow-up assessment. Hence, it would be preferable to have follow-up of the patients involved for longer periods.

From the results of current and previous studies, it could be concluded that weight bearing exercises program have a significant improvement in bone mineral density, measured by DEXA.

\section{Conflicts of interest: None \\ REFERENCES}

[1]. Mok CC, Lee KW, Ho CTK, Lau CS, Wong RWS. A prospective study of survival and prognostic indicators of systemic lupus erythematosus in a southern Chinese population. Rheumatology (Oxford) 2000;39:399-406.

[2]. Abu-Shakra M, Urowitz MB, Gladman DD, Gough J. Mortality studies in systemic lupus erythematosus. Results from a single center. II. Predictor variables for mortality. J Rheumatol,1995;22:1265-1270.

[3]. Zonana-Nacach A, Barr SG, Magder LS, Petri M. Damage in systemic lupus erythematosus and its association with corticosteroids. Arthritis Rheum 2000;43:1801-1808.

[4]. Mok CC, Ho CTK, Wong RWS, Lau CS. Damage accrual in southern Chinese patients with systemic lupus - erythematosus. J Rheumatol 2003;30:1513-1519.

[5]. Haugeberg G, Griffiths B, Sokoll KB, Emery P. Bone loss in patients treated with pulses of methylprednisolone is not negligible: A short term prospective observational study. Ann Rheum Dis 2004;63:9404.

[6]. Fitzpatrick LA. Glucocorticoid-induced osteoporosis. In: Marcus R, editor. Osteoporosis. Blackwell Science. Boston, MA: 1994. p. 202-26.

[7]. Sinigaglia L, Varenna M, Binelli L et al. Determinants of bone mass in systemic lupus erythematosus: a cross sectional study on premenopausal women. J Rheumatol 1999;26:1280-1284.

[8]. Li EK, Tam LS, Young RP, Ko GT, Li M, Lau EM. Loss of bone mineral density in Chinese pre-menopausal women with systemic lupus erythematosus treated with corticosteroids. Br J Rheumatol 1998;37:405410.

[9]. Kipen Y, Buchbinder R, Forbes A, Strauss B, Littlejohn $G$, Morand E. Prevalence of reduced bone mineral density in systemic lupus erythematosus and the role of steroids. J Rheumatol 1997;24:1922-1929.

[10]. Bhattoa HP, Bettembuk P, Balogh A, Szegedi G, Kiss E. Bone mineral density in women with systemic lupus erythematosus. Clin Rheumatol 2002;21:135141.

[11]. Gilboe IM, Kvien TK, Haugeberg G, Husby G. Bone mineral density in systemic lupus erythematosus: comparison with rheumatoid arthritis and healthy controls. Ann Rheum Dis 2000;59:110-115.

[12]. Pons F, Peris P, Guanabens N et al. The effect of systemic lupus erythematosus and long-term steroid therapy on bone mass in premenopausal women. Br J Rheumatol 1995;34:742-746.

[13]. Formiga F, Moga I, Nolla JM, Pac M, Mitjavila F, Roig-Escofet $D$. Loss of bone mineral density in premenopausal women with systemic lupus erythematosus. Ann Rheum Dis 1995;54:274-276.

[14]. Edwards B.J. and Migliorati C.A., Osteoporosis and its implications for dental patients. J Am Dent Assoc; 2008;139(5):545-52.

[15]. Ferrar L., Roux C., Reid D.M. Felsenberg D., Gluer C.C.and Eastell R. Prevalence of non-fracture short vertebral height is similar in premenopausal and postmenopausal women: The osteoporosis and ultrasound study. Osteoporos Int. 2012;23(3):103540.

[16]. Seigrist M. Role of physical activity in the prevention of osteoporosis." Mineral Res. 2008;10:13031311.

[17]. Glüer CC. Monitoring skeletal changes by radiological techniques. J Bone Miner Res 1999;14:195262.

[18]. Hakan L., Anna S., Ulrika P. and Gustaf B. Weight bearing exercise and osteoporosis." Osteo Int. 2005;16:1117-1123.

[19]. Fogelman I, Blake GM. Different approaches to bone densitometry. J Nucl Med. 2004;41:2015-25.

[20]. Mishra L., Mahavir B., Shanu N. and Ranu S. Dental care in the patients with bisphosphonates therapy." 
International Journal of Dental Clinics 2011;3(1): 60-64.

[21]. Blake G.M., Glen M., Fogelman and Ignac. Effect of bone strontium on BMD measurements. Journal of Clinical Densitometry 2007;10(1):34-38.

[22]. Manolagas S, Jilka R. Emerging insights into the pathophysiology of osteoporosis. N Engl J Med 1995;332:305-311.

[23]. Bultink I, Lems W, Kostense P, Dijkmans B, Voskuyl E. Prevalence of and risk factors for low bone mineral density and vertebral fractures in patients with systemic lupus erythematosus. Arthritis Rheum 2005;54:2044-2050.

[24]. Kipen Y, Briganti E, Strauss B, Will R, Littlejohn G, Morand $E$. Three year followup of bone mineral density change in premenopausal women with systemic lupus erythematosus. J Rheumatol 1999;26:310317.

[25]. Kai M.C., Anderson M. and Lau E.M. Exercise interventions: Defusing the world's osteoporosis time bomb." Bull world health organ 2012;81(11):827830.

[26]. Qin L., Au S.K., Choy Y.W., Leung P.C., Neff M. and Lee K.M. Regular Tai Chi exercise may retard bone loss in postmenopausal women: A case-control study." Archives of Physical Medicine and Rehabilitation 2002;83:1355-1359.
[27]. Seigrist M. Role of physical activity in the prevention of osteoporosis. Mineral Res; 2008;10:13031311.

[28]. Kohert W.M., Bloomfield S.A., Little K.D., Nelson M.E., and Yingling V.R., American college of sports medicine. Standing position, physical activity and bone health" Med Sci Sports Exer. 2004;36(11):1985-1996.

[29]. Rockville M.D. Bone Health and Osteoporosis: A Report of the Surgeon General, US Department of Health and Human Services, Office of the Surgeon General. 2004;171-177.

[30]. Bouxsein M.L. Determinants of skeletal fragility." Best Pract Res Clin Rheumatol 2005;19:897-911.

[31]. Meka N., Katragadda S., and Cherian B. Endurance exercise and resistance training in cardiovascular disease. Cardiovas Disorders; 2008;7:21-26.

[32]. Caplan G.A., Ward J.A. and Stephen R., Lord the benefits of exercise in postmenopausal women. Austr J Pub Hlth, 2010;17(1):23-26.

How to cite this article:

Instar S. Waked. EFFICACY OF WEIGHT BEARING EXERCISES FOR SYSTEMIC LUPUS ERYTHEMATOSUS PATIENTS SUFFERED FROM OSTEOPOROSIS. Int J Physiother Res 2017;5(6):2482-2489. DOI: 10.16965/ijpr.2017.234 